\title{
Towards Environmental Disclosure of Chinese Listed Companies: A Paper Making \& Printing Industry Perspective
}

\author{
X. H. Meng ${ }^{1,2}$ D. Li ${ }^{1}$ Z. Zhang ${ }^{1}$ \\ ${ }^{1}$ School of Politics and Public Administration, Soochow University, 215123, China \\ ${ }^{2}$ Antai School of Management, Shanghai Jiaotong University, 200052, China
}

\begin{abstract}
Corporate environmental disclosure as an effective tool of environmental management has been widely concerned. We focus on the environmental disclosure towards the firms in the industry of paper making \& printing in China. Using content analysis of corporate annual reports and CSR reports in three years, 2008, 2009 and 2010, we investigate the status quo of environmental disclosure in this heavy pollution industry. The pattern, content and level of environmental disclosure are demonstrated, and then the deficiencies of corporate environmental disclosure are put forward. Finally, we proposed the suggestions for regulation on Chinese corporate environmental disclosure.
\end{abstract}

Keywords: Environmental Disclosure, Corporate Social Responsibility (CSR), Listed Companies

\section{Introduction}

Currently in China, environmental pollution and ecological imbalance have caused a series of serious events, which made environmental disclosure a statewide concern.

China State Environmental Protection Administration (SEPA) issued the Environmental Information Disclosure Rules in $2007^{[1]}$. Based on the rules of SEPA,
Shanghai Stock Exchange issued another regulation in 2008, Strengthening CSR of listed companies and Guidelines of Environmental Information Disclosure for Chinese Listed Companies, towards Chinese listed companies requiring firms to proactively fulfill CSR (including environmental responsibility). Many companies disclosed certain environmental information in their annual reports, some even with a stand-alone report on environmental practices. Environmental information disclosure is a component of corporate social responsibility ${ }^{[2,3]}$. Then, it arises one question that what is the status quo of corporate environmental disclosure practice and what deficiencies still exist since the environmental disclosure rules issued in 2007 and 2008. This paper will investigate the corporate environmental disclosure from the industrial perspective of paper making and printing industry.

Although the printing technology have gone through the second revolution in the 20th century and eliminated the lead row and stamping process, however, many printing enterprises in China still adopt traditional printing process resulting in some environmental problems (e.g., organic solvent volatilization, waste water discharge). Wastewater of pulp and paper industry accounts for $10 \%-12 \%$ of the total wastewater in China, and ranks the third highest discharge industry; chemical oxygen consumption of wastewater ac- 
counts for $40 \%-45 \%$ of national total emissions, and ranks first in $2008^{[4]}$. It shows that the paper making and printing industry is still one of the serious pollution industries. However, so far, not all of the paper making and printing listed companies have positively responded to the requirements of SEPA and disclosed according environmental information. In addition, less academic research has focused on environmental disclosure towards the paper making \& printing industry. This study focuses on this heavy pollution industry, discusses the ways, content, level, and the existing deficiencies of environmental disclosure, and thereby puts forward countermeasure proposals.

\section{Methods}

The investigated firms in the paper making \& printing industry are selected from public companies listed in the main board markets and issued ' $A$ ' stock in Shanghai and Shenzhen Stock Exchanges in China. In addition, the sampled firm must meet the following two criteria: (1) Having gone public before December 31, 2006 so as to avoid the "window-dressing" effect at the early stage of going public; and (2) Excluding the cases with industry turnover during the research period, 2008-2010. After screening, 18 listed companies in the paper making $\&$ printing industry are obtained from 2006 to 2008. Data on environmental disclosure are abstracted from 54 annul reports and 20 stand-alone reports of 18 sampled firms.

The level of corporate environmental disclosure is gauged using content analysis. Nine items of content analysis are identified (see Table 2) according to the regulation issued by SEPA in 2007 and Shanghai Stock Exchange in 2008. Indexing technique is adopted to quantify the level of environmental disclosure. Each item is scored and ranges between 0 and 3,3 if item described in quantitative terms, 2 if item described specifically but qualitatively, 1 if item described in general, and 0 if no information ${ }^{[5,6]}$.

\section{Results and Discussions}

\subsection{Proportion and ways of environ- mental disclosure}

Proportion of environment disclosure in CSR report is low. Table 1 shows that there is one-third of the companies, that is, 6 firms in 18 paper making \& printing companies disclosed CSR report in 2008, and 7 firms (about 38.9\%) with CSR reports both in 2009 and 2010. The longest CSR report is 12 pages, while the shortest only 3 pages. As shown in Table 1, environmental information is only a small part of CSR report according to the pages of environmental disclosure. So far, the ratio of companies with environmental disclosure (including in annual reports) in the industry of paper making \& printing are not more than $50 \%$. The reasons are that, on the one hand, in the context of the extensive style of economic growth strategy in China, enterprises have little proactive consciousness of environmental management; on the other hand, unclear incentives and low cost of environmental violation, imperfect system of supervision, and possible negative effects of disclose environmental information, resulted in the majority of companies unwillingly taking the initiative to environmental management and disclosure.

Qualitative disclosures dominate the reports. Only 4 listed companies in the sample took the quantitative way of environmental disclosure, and about half of the companies with environmental disclosure in a way of simple qualitative description (see Table 1). However, based on content analysis, we also found that some enterprises gradually transferred the way of qualitative disclosure to quantitative disclosure. For example, HUATAI Paper disclosed its environmental infor- 
mation in CSR report in 2009 in a qualitative way as follows: "We promote the development of national paper and construct a green HUATAI, adheres to create value in all products and reduce the environmental load of product in whole life cycle at the same time. For contribution to national sustainable development, effective environmental management is implemented in the process of production (e.g., saving energy, waste reduction, operation of environment management system) to improve the environmental performance. Proactive participation in the environmental protection and other public welfare activities is to make contributions to society". While CSR report in 2010 was described in a quantitative way as follows: “... nearly 50,000 cubic meters of biogas per day produced by the anaerobic water treatment, were all transformed to 600,000 kilowatts of thermal power generation and saved energy equivalent to 17,000 tons of standard coal; investment of 15 million Chinese Yuan to introduced three sets of world-class wastewater treatment system, and to build a water treatment plant as the Asian largest and most advanced equipment .... Using the advanced treatment process, drainage COD dropped to $60 \mathrm{mg} / \mathrm{l}$ below which made the system become an international water treatment model project...."

Form of environmental disclosure form is not standard. First, only a few of the sampled companies have opened standalone CSR report. However, most of the firms with environmental disclosure still chose the channel of annual reports to disclose environment information, or disclosed environment information together with other announcements, which is not easy to be collected and supervised by the public. Second, even for those firms with CSR report, they still have not a unified disclosure form or industrial standard, and disclosed in accordance with their own selection though the SEPA have issued what should be disclosed. For example, some companies tended to stress energy saving and emission reduction in the CSR report (e.g., 600163), some companies paid attention to technological innovation related to environmental protection (e.g., 600836), and some companies generally described in many aspects but no detailed elaboration (e.g., 600966).

Distribution of environmental disclosure is uneven among the companies. A few firms disclosed no or little environmental information since 2008, only about 4 companies disclosed more information, which produced a grave polarization. Furthermore, even for the companies with environmental disclosure, there are only one or two companies which have stable, detailed and fairly much disclosure of environmental information.

\subsection{Content of environmental disclo- sure}

Level of environmental disclosure content is not high. Various issues of environmental information were disclosed (e, g., waste treatment and recycling, energy saving and emission reduction, internal environmental training, promotion of the surrounding environment, ISO system authentication, environmental investment and technology, and environmental awards, etc.). As Table 2 shown, the scores are the lowest in the three aspects of top executive's environmental awareness, pollutants discharge and resources consumption, and public environmental welfare such as afforestation and potential environmental impacts. It indicates that environment consciousness and pollutant control should be strengthened. In the aspects of pollutant discharge and resource consumption, and conformity with environmental regulations or norms, the information was less quantitative described, and only 2 firms specifically disclosed the discharge of harmful materials, 
8 companies mentioned the reduced emissions of pollutants or just simply said the emissions had met national environmental standard but did not elaborate the type, quantity and destination of solid waste/toxic substances disposal or treatment.

Information of environment disclosure is general and selective. We can see from Table 2 that more information related to the general environmental description (e.g., environmental protection policy, goals and organization) and insensitive environmental contents (e.g., ISO system authentication and environmental management initiatives, technology and investment, and promotion of environmental performance) were disclosed, while, as mentioned above, the specific type and quantity and thereby the impacts on natural environmental were rarely mentioned. For example, Meili Paper in its CSR report said that according to national policy, they have gradually construct the alkali recovery system, wastewater comprehensive treatment system, forest base irrigation pond in processing wastewater, electric field electrostatic precipitator and water film filter. Automatic on-line monitoring facilities were built in the main pollutant discharges. All kinds of measures were taken to ensure the normal operation of environment facilities and all kinds of pollutants discharged within environmental standards which made the smooth completion of company's 2010 annual goals of energy conservation and emission reduction.

Lack of third-party audit. Although AA1000 Assurance Standards was issued by Institute of Social and Ethical Accountability as well as the quantity of environmental disclosure and CSR reports are increasing, there are no sampled companies audited by third party on environmental disclosure in paper making \& printing to ensure true and complete environmental information.
Table 1: Environmental disclosure in CSR report in the paper making \& printing industry

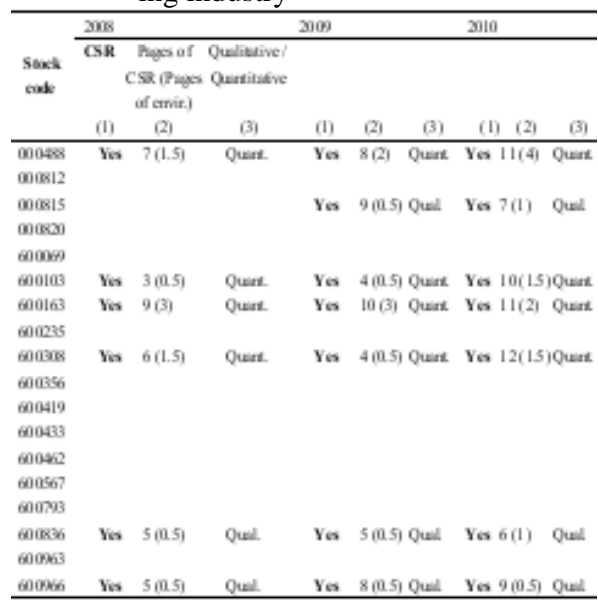

Table 2: Environmental disclosure content and level of 18 paper making \& printing firms

\begin{tabular}{|c|c|c|c|c|c|c|}
\hline \multirow{2}{*}{$\begin{array}{c}\text { Ioems } \\
\text { of conoe at } \\
\text { a analy sis }\end{array}$} & \multicolumn{3}{|c|}{$\begin{array}{l}\text { Number of Firms } \\
\text { disclosing the item }\end{array}$} & \multicolumn{3}{|c|}{ A verage score } \\
\hline & 2008 & 2009 & 2010 & 2008 & 2009 & 2010 \\
\hline $1_{1}$ & 5 & $T$ & $T$ & 0.56 & 0.78 & 0.78 \\
\hline $1_{2}$ & 11 & 11 & 11 & 0.81 & 1.06 & 0.94 \\
\hline $1_{3}$ & 14 & 14 & 16 & 0.32 & 0.38 & 0.51 \\
\hline 14 & 16 & 16 & 17 & 1.19 & 1.23 & 1.33 \\
\hline $1_{s}$ & 2 & 1 & 2 & 0.06 & 0.03 & 0.08 \\
\hline 16 & 15 & 15 & 14 & 0.83 & 0.71 & 0.85 \\
\hline $1_{7}$ & $\mathrm{~s}$ & 5 & 13 & 0.12 & 0.08 & 0.29 \\
\hline $1_{s}$ & $T$ & 5 & 8 & 0.19 & 0.09 & 0.12 \\
\hline 14 & 5 & 4 & 2 & 0.15 & 0.11 & 0.04 \\
\hline
\end{tabular}

Note: $I_{1}$ : Top executive's statement on values of environmental protection. $\mathrm{I}_{2}$ : Environmental protection policy, goals and organization. $\mathrm{I}_{3}$ : ISO system authentication and environmental management initiatives. $\mathrm{I}_{4}$ Technology and investment related to the environment. $\mathrm{I}_{5}$ : Pollutants discharge and resources consumption. $\mathrm{I}_{6}$ : Promotion of environmental performance. I7: Significant environmental issues and environmental impact. $\mathrm{I}_{8}$ : Conformity with environmental regulations or norms. I9: Environmental public welfare activities and others.

\subsection{Special environmental honors and penalty}

After investigated the 18 companies in paper making \& printing industry, we found that there are 6 companies that got the national or industrial rewards and honors related to environmental protection. The remaining companies with CSR 
report but without directly awarded the honors of environmental protection, also obtained financial or technical support from government. Therefore, it indicates that the firms with proactively strategy of fulfilling their environmental responsibilities are more likely to voluntarily disclose environmental information, and are easier in turn to get the government environmental incentives and supports.

The Ministry of Environment of China has criticized and exposed the list of firms including 54 listed companies which failed to conform to national environmental regulation in 2010 . There were two companies in paper making \& printing industry. Surprisingly, they both obtained honors of environmental protection. Of the two firms, one has potential environmental risk; the other resulted in gas pollution. The two companies disclosed more information to show their efforts and embody environmental legitimacy.

\section{Conclusions and implications}

Based on content analysis of annual and CSR reports of Chinese listed companies in the heavy pollution industry of paper making \& printing, we concluded that the quantity of proactive environmental disclosure increased gradually but there are still many issues of environmental disclosure that need to be addressed (e.g., low proportion of environment disclosure in CSR report, more qualitative rather than quantitative disclosure, various forms without uniform standard, selective environment information, low level of environmental content, and lack of third-party audit). In addition, proactive environmental disclosure is linked with governmental support. The findings have important implications for regulator. First, the government would encourage firms to voluntarily disclose additional environmental information, and set up more detailed and mandatory regulations to guide corporate environmental disclosure. Second, it needs to smooth the ways for external stakeholders (e.g., the public, media, suppliers, consumers, communities) to easier access corporate environmental management. Third, it is necessary to standardize the environmental disclosure form and content and initiate CSR report or standalone environment report as main documents to disclose environmental information. Finally, third-party audit should be introduced into CSR with reference to developed countries and a suitable audit standard should be established for Chinese listed companies.

\section{Acknowledgements}

This work was financially supported by the Soft Science of Shanghai S\&T Development Foundation (12692191700).

\section{References}

[1] http://www.mep.gov.cn/gkml/.

[2] A.R. Rahman, T.M. Tay, B.K. Ong, and S. Cai, "Quarterly reporting in a voluntary disclosure environment: Its benefits, drawbacks and determinants," The International Journal of Accounting, 2007, 42(4), pp.416-442.

[3] H.S. Brown, M.J. Jong and D.L. Levy, "Building institutions based on information disclosure: Lessons from GRI's sustainability reporting," Journal of Cleaner Production, 2009, 17(4), pp.570-580.

[4] http://www.zcom.com/article/6883.

[5] C.H. Cho and D.M. Patten, "The role of environmental disclosures as tools of legitimacy: A research note," Accounting, Organizations and Society, 2007, 32(7-8), pp.639-647.

[6] J. Wiseman, "An evaluation of environmental disclosures made in corporate annual reports," Accounting, Organizations and Society, 1982, 7(1), pp.53-63. 